\title{
Risk management in local authorities: an application of Schatzki's social site ontology
}

\section{Binh Bui}

School of Accounting and Commercial Law

Victoria University of Wellington

Wellington, 6140, New Zealand

Phone: +64(0)4-463-6679

Email: binh.bui@vuw.ac.nz

\section{Carolyn Cordery*}

Aston Business School

Aston University

Birmingham B4 7ET

Phone: +44(0)121-204-3380

Email: c.cordery@aston.ac.uk

\section{Zhichao (Alex) Wang}

Research School of Accounting

College of Business and Economics

The Australian National University

Canberra, 0200, Australia

Phone: $+61(0) 2-612-57374$

Email: alex.wang@anu.edu.au

\begin{abstract}
Prior research has devoted limited attention to studying changes in organisational risk management (RM) practices. This is despite continuous dissatisfaction from academics and practitioners with organisations' ability to manage risks. We draw on Schatzki's social site ontology to study RM practices of two New Zealand local authorities that both experienced (earthquake) risk events and whose RM practices could be expected to change. We extend recent research utilising Schatzki, by finding that practical intelligibility and general understanding mutually affect each other in the organising of practices. Further, we extend Nama and Lowe's (2014) addition to Schatzki by highlighting the importance of including teleological structures and accounting devices into the mutually constitutive relationship between general understanding and affectivity. Finally, we contribute to RM literature by proposing that changing the general understanding (in addition to the mere implementation of $\mathrm{RM}$ tools) is an important way of making RM change fundamental and sustainable.

Key Words: accounting; risk management; Schatzki's social site ontology; practice theory; qualitative case study
\end{abstract}




\section{Risk management in local authorities: an application of Schatzki's social site ontology}

\section{Introduction}

Public sector organisations operate in dynamic and complex environments. Their multiple stakeholders may impose undue demands and judge performance using diverse criteria (Bryson, 1988). Good corporate governance enables public sector organisations to meet these demands, while simultaneously pursuing political, economic and social objectives (Collier \& Woods, 2011). Corporate governance reforms require risk management (RM), as part of management controls, to reflect corporate risk appetites and assist in achieving corporate objectives (Abernethy \& Chua, 1996; Clarke \& Varma, 1999; Collier \& Woods, 2011). RM is said to have the potential to enable local authorities (LAs), with the responsibility for a broad range of public services and politically-active citizens, to be effectively governed and deliver improved organisational performance (McCrae \& Balthazor, 2000). As such, a set of RM frameworks (e.g. Enterprise Risk Management) has been developed (e.g. Beasley et al. 2010; Collier et al., 2007), which prescribe fundamental RM principles and standard procedures for public sector organisations (like LAs) to deal with regular operational risks (e.g. Vinnari and Skærbæk, 2014). Yet contingent theorists note that contextual variables surrounding organisations' operations affect RM framework choice (e.g. Mikes \& Kaplan 2013; Woods, 2009a).

Further, the implementation and operationalisation of RM frameworks resemble a 'black box' prised open by recent research (Gurd \& Hellier, 2017; Lim et al., 2017; Meidell \& Kaarbøe, 2017; Fischer \& Ferlie, 2013; Hall et al., 2015). These RM case studies examine how different groups of people act on and are acted upon by technical tools (including RM frameworks and accounting devices), how these tools influence decision-making processes and organisational RM practices, and the difficulties, conflicts and paradoxes arising therein. Research has also called for studies of how RM is integrated into daily decision-making, business operations and individuals' behaviour (Zolkos, 2008; Bruno-Britz, 2009; Arena et al., 2010). However, there has been no discussion of changes in RM practices, especially comparing public sector organisations. Generally, research finds that organisational RM practice may fail, cause uncertainties, or lead to the creation of new risks (Power, 2007; 2009; Vinnari \& Skærbæk, 2014). It is inevitable that organisations will respond to actualised risk occurrence and emergent risks. This is likely to result in changes in RM practice. Research to understand changes in RM practice would therefore enable better RM and enhanced theorisation of public sector risk management. Motivated by this gap, this research asks: How 
is risk management practice organised and how does it change within LAs? To address this question, we analyse RM and accounting practices through practice theory. Specifically, we adopt Schatzki's (2002) social site ontology that understands RM practices as bundles of human activity (comprising rules, understandings and teleo-affective structures) and material arrangements.

We study two LAs in New Zealand (NZ) both experiencing and responding to major earthquakes (seismic events), which are ideal for insights into LAs' organisation and changes in RM practice. These two LAs experienced similar major risk events in a similar time-frame enabling comparative insights into the extent of responsiveness to risk events, which a single case study does not afford. We expected, based on our preliminary analysis, that one LA, being proximate to an active seismic fault, is prepared and responsive to major earthquakes, while the other LA is unprepared with low prior seismic activity. Hence, the latter should undertake more extensive adaptations following the risk event. The case study choice follows theoretical sampling allowing 'making comparisons' and to 'maximise opportunities to discover variations' in organisational characteristics, the impact on RM practices and changes subsequent to similar risk events (Strauss \& Corbin, 1998, p.201) .

Empirically, RM practices within the two LAs are organised through interactions between organisational RM rules/frameworks, practical intelligibilities, and RM teleologies, affectivity and accounting devices (as per Schatzki, 2002). Overarching these are two general understandings - "open judgement" and "insular thinking”. These general RM attitudes are highly attributable to each Chief Executive's (CE's) practical intelligbility without which the development of such general understanding would not be possible. These general understandings at the same time partially frame operational staff's mind-set on how risks should be managed, and override the rules-based practical understanding in determining these individuals' RM actions. In this sense, we argue practical intelligibility and general understanding mutually affect each other. This extends prior research by showing how practical intelligibility interacts with other Schatzki elements in organising certain practices. Further, we show that end-project-task combinations and accounting devices may be structured to influence affectivity, which in turn shapes general understanding of RM practices within the two LAs. In addition, the general understanding affects individuals' emotions and moods, and thus how they perform end-project-task combinations and utilise accounting devices in everyday RM practcies. We thus extend Nama and Lowe (2014) and Schatzki by proposing the inclusion of teleological structures and accounting devices into the mutually constitutive relationship 
between general understanding and affectivity. Finally, this study builds on Fisher and Ferlie (2013) and Hall et al. (2015) by proposing that changing the general understanding (in addition to the mere implementation of RM tools) is an important way of making RM change fundamental and sustainable. We show that the change of general understanding following the actualisation of risk events may change people's emotions that have previously been found to drive resistance to $\mathrm{RM}$ change. These new emotions in turn are likely to fundamentally and persistently change individuals' daily RM activities.

The next section reviews extant literature on RM practices, particularly within public sector organisations. Following an overview of Schatzki's social site analysis, the research methods are outlined. Then, the findings are presented and RM practices in the two LAs analysed by insights regarding the nature and dynamics of Schatzki's four elements. Finally, contributions, limitations and directions for future research conclude the paper.

\section{Risk Management Practices}

Risk awareness is stimulated by escalating business scandals, natural disasters, terrorist attacks and problems in emerging virtual markets. As such, RM permeates people's daily lives and organisations' everyday operations (Power, 2004). Unsurprisingly, prescriptive frameworks such as the COSO Enterprise Risk Management (ERM) Framework and the International Standards Organisation's (ISO) 31000: 2009, Risk Management - Principles and Guidelines on implementation evolve to guide organisations' RM. ERM specifies actions to manage organisational risks including: risk identification, risk assessment, risk reduction, monitoring and control, adapted to organisations' risk appetites (Themsen, 2014). Accounting should assist in operationalising ERM and similar RM frameworks through quantifying the probability of risk occurrence and severity of risk consequences; calculating risk tolerance/appetite; and performing RM cost/benefit analyses (COSO, 2004; Mikes, 2011; Paape \& Speklè, 2012). Such prescriptive RM frameworks and accounting functions provide tangible processes to manage regular operational risks, and influence decision-making through vertically selling new ideas and risk technologies to top management, and horizonally influencing managers to use risk knowledge (Meidell \& Kaarbøe, 2017). Through reducing risk exposure, RM frameworks and processes can improve organisational performance (Florio \& Leoni, 2017).

Despite the increasing popularity of ERM and similar prescriptive RM frameworks, some researchers question their effectiveness (Mikes \& Kaplan, 2013). Prescriptive RM frameworks 
can result in 'box-ticking' (Collier et al., 2007), or merely complying with pre-determined rules and processes. RM frameworks may even create second order risk or lead to the "risk management of nothing' (Power, 2007; 2009). Practitioners also express dissatisfaction with these frameworks (CFO Research Services \& Towers Perrin, 2008; Beasley et al., 2010). Such doubts have turned researchers' attentions to contingent/contextual variables influencing RM framework adoption. Researchers find that boards and executive teams, internal risk specialists, risk type, the level of firms' financial distress, firm size, industry affiliation, regulatory pressure, institutional ownership and auditor influence are associated with ERM adoption (Kleffner et al., 2003; Desender, 2007; Pagach \& Warr, 2011; Paape \& Speklé, 2012; Mikes \& Kaplan, 2013). Woods (2009a) finds choice of risk control systems in public organisations depends on central government policies, information and communication technology, and firm size. Anderson et al. (2015) (studying inter-firm alliances) find formal controls are used to manage performance and relational risk, while firms facing compliance and regulatory risks tend to use informal controls. Woods (2009b) documents significant variations in the formalisation and complexity of RM systems in two UK organisations. Similarly, variations were found in studies into UK LAs (Crawford \& Stein 2004) and Australian LAs (Barrett, 2005; CPA Australia, 2002). Mikes (2009) argues that organisational culture is a significant contributor to such variety.

Contingency theorists enhance our RM understanding by connecting prescriptive RM frameworks or 'best RM practices' to various contextual variables of regular operational risks. However, recent research, such as Power (2009) and Vinnari and Skærbæk (2014), argue that $\mathrm{RM}$ is more complex than merely matching a system to context. They call for studies of selection, implementation, use and operationalisation of RM systems for regular operational risks. Recent studies extend practice-based RM research by considering micro-level RM actions. In their bank case, Hall et al. (2015) find risk managers intentionally include others in developing RM tools by incorporating their feedback and knowledge and expressing explicitly their importance. By 'including other people', risk managers establish common ground between themselves and relevant organisational actors, increasing the communicability and acceptability of their RM plans and activities.

While risk managers are influential in top management's decision-making processes, Fischer and Ferlie's (2013) longitudinal study of UK mental health care shows subordinates are strongly emotionally attached to implicitly self-regulated RM norms. Emotional attachment leads these subordinates to resist their superiors' attempts to import and implement external 
rule-based RM regimes (such as ERM). These emotions create enduring tensions between two RM regimes (Fischer \& Ferlie, 2013). Using two cases, Gurd and Hellier (2017) demonstrate reconciliation and balancing of creativity and innovation with admistrative needs through organisational RM and management control. Practice in their organisations differ significantly; one ignores RM and management control systems completely, maintaining an innovation focus, while the other implements these systems but innovation fails to create value. In both, engineers rather than accountants operationalise RM and management control. Alternative RM (im)balances and conflicts are revealed by Lim et al. (2017) in Singapore banks, where frontand back-offices have significant differences in risk perceptions and understandings. Performance measurement and remuneration systems (management controls) that encourage a revenue-focus make the adoption of a three-lines-of-defence RM model (which aims to split responsibilities) ineffective. The RM model reinforces existing tensions and paradoxes. Indepth understanding of behavioural dimensions is thus required (Lim et al., 2017).

These qualitative studies demonstrate (sources of) variations of RM practices. However, except for Fischer and Ferlie's (2013), there are still limited understandings of RM practice changes, especially public sector comparisons. Research to understand changes in RM practice may enable enhanced theorisation of public sector risk management and offer solutions to academics and practitioners' continuous dissatisfactions with RM of regular operational risks (Power, 2009; Vinnari \& Skærbæk, 2014).

\section{Schatzki's Social Site Ontology}

Practice theories are useful to explain organisational phenomena across various disciplines (Nama \& Lowe, 2014). These theories are particularly pertinent to understand holistically how LAs' RM practice changes, especially following risk occurrence. Specifically, in order to understand the operationalisation of the RM rules/frameworks, RM teleologies and accounting devices as well as practical intelligibilities and affectivity, we employ Schatzki's (2001a, 2001b, 2002, 2012) practice theory. Schatzki's is acknowledged arguably as the strongest practice-based theory (Nama \& Lowe, 2014). Ahrens and Chapman (2007) and Jorgenson and Messner (2010) argue that Schatzki's social site ontology can link organisations' accounting and operationalisation of strategy, to uncover the "situated functionality" of management control practices. Thus, Schatzki's practice theory is pertinent to explain accounting and RM in public sector organisations, particularly to examine LAs' everyday activities and how they interact, respond, converge, or deviate from RM objectives. 
According to Schatzki's (2002) practice theory, organisational sites comprise a set of practices. Practices are unique, but intelligently coexist and connect. Public sector RM involves routine processes of adopting, implementing and using certain ERM (Crawford \& Stein, 2004; Collier \& Woods, 2011). ERM forms a 'practice' as evidenced by continuous controversies between organisational actors (Mahama \& Yu Ming, 2009; Callon, 2007); reliance on personal and organisational culture (Mikes, 2011) and mobilisation of inscriptions and other material devices (Vinnari \& Skærbæck, 2014). We now describe Schatzki's elements as actions or material arrangements.

Any practice (including RM) comprises a nexus of actions and material arrangements which, to be sustained, follow a certain order (Schatzki, 2002). Actions are organised by four phenomenon: (1) teleo-affective structures, (2) rules, (3) practical understandings, and (4) general understandings, as now described.

$\underline{\text { Teleo-affective structures }}$ are practice properties, comprising teleology, affectivity, and related structural arrangements. Teleology embraces practice ends and/or goals. For example, the goal of private equity practice is to 'generate superior, "top quartile" returns to investors/LPs' (Nama \& Lowe, 2014 p. 289) while in education, practice ends are educating people (Schatzki, 2002). In LAs we expect these to be focused on meeting multiple stakeholder demands in delivering their political and economic and social objectives. To realise RM practice teleology, staff/management pursue and execute projects and tasks structured to manage risks. Further, staff/management experience emotions (affections - Schatzki, 2002) like love and fear, which arise while executing these RM projects and tasks. Affectivity likely affects the achievement of teleological ends (Boedker \& Chua, 2013), indeed teleology and affectivity interweave and determine participants' commitments to operationalising RM. Teleo-affective structures affect/are affected by RM rules and understandings. When: 'understandings, rules, ends, and tasks are incorporated into participants' minds via their "mental states"; understandings, for instance, become individual know-how, rules become objects of belief, and ends become objects of desire' (Schatzki, 2002, p.480). As such, RM practice in public sector organisations transcends RM frameworks, reliance on RM culture or deploying technical analysis; due to rules, understandings and teleo-affective structures.

For public sector RM, rules could be external frameworks or internally developed "best practice". RM rules become legitimated principles to achieve organisations' objectives. Rules also prescribe how risk is evaluated, considered in decision-making, application and compliance with RM frameworks. However, ambiguities exist. For example, when rules are 
unsuccessful (Bromiley et al., 2015), deviate or conflict with organisations' beliefs and traditional RM, practical understandings may prevail when operationalising RM. Practical understandings relate to practice actions: 'knowing how to X, knowing how to identify X-ings, and knowing how to prompt as well respond to X-ings' (Schatzki, 2002b, p.77). Organisations' implicit norms (e.g. as promoted by top management) inform people's practical understandings of how to perform projects and tasks governed by RM rules. However, Schatzki (2001b) would argue that practical intelligibility determines people's RM actions. Practical intelligibility (what makes sense) is individualist (Nama \& Lowe, 2014); related to personal goals, training, education and experience, prior knowledge of similar events and so on. It may result in RM rules being practised differently within an organisation - obeyed by some; modified by others, or even violated.

While practical understanding relates to individuals knowing what actions to take and how, general understandings are practice elements reflecting people's attitudes to performing an action (Schatzki, 2001b). These pervasive attitudes are shared by most people within a practice, and expressed in everyday sayings and doings. Nama and Lowe (2014) connect Schatzki's general understanding to mattering. 'Wonder and goodness and satisfaction are aspects [of general understanding] related to "how things matter"" (Nama \& Lowe, 2014, p.300). They propose a mutual constitutive relationship between general understandings and affectivity whereby people's emotional attachment and sensitivity to certain RM actions may be driven by their understanding about these actions' importance. Alternatively, affectivity may drive how RM actions matter because 'how one perceives, how one argues and what one accepts as cogent or definitive are affected by ones' moods' (Schatzki, 2002, pp. 56-57).

Schatzki (2002) notes actions are inter-related through: (i) chains (or sequences) of interrelated actions and (ii) commonalities/orchestrations. For example, to achieve certain public-related objectives, management may design a set of RM rules and require compliance. In participating, people respond to each other (Weick \& Roberts, 1993). By agreeing, understanding and appreciating one another's actions, they develop shared understandings (commonalities) of the meaning of risk and its management. Nevertheless, if participants' interpretations differ, these orchestrations allow different simultaneous interpretations of the rules.

Additionally, Schatzki (2002) recognises material arrangements are important in linking to chains of actions. Material arrangements include human beings, artefacts, other organisms, and the setting within which people act. These connect and mediate different actions. For example, 
RM officers (human beings) connect and evaluate risk actions between different organisational levels/departments. Also, accounting formulations (artefacts) create a space of 'intelligibility' highlighting RM activities' financial importance. Commonalities occur around imprecise accounting formulations, yet orchestrations promote innovations when those with different interests freely express their opinions (Jorgensen \& Messner, 2007). Ahrens and Chapman (2007) state accounting calculations are artefacts, facilitating mutuality between strategic financial objectives and local shop-level operational practices in a UK restaurant chain. Accounting (artefacts) may promote and circulate certain affections, fusing individual efforts to achieve certain common organisational objectives (Boedker \& Chua, 2013). Schatzki (2002) encourages examinations of how material arrangements organise multiple actions in a certain order and sustain commonalities and orchestrations among actions. We now describe our research method.

\section{Research Methods}

This research adopted the case study method as it facilitates a deeper understanding of complex social phenomena and novel issues, such as RM practice (Horton et al., 2004; Woods, 2009a). We chose two New Zealand LAs as case studies - Wellington City Council (WCC) and Christchurch City Council (CCC). These two LAs are relatively similarly sized, avoiding size-driven differences in RM practices. The cases enable theoretical sampling (Yin, 1993) whereby differences potentially lead to variations in the patterns of phenomenon (theoretical explanations), hence theory validation. The two cities where the two LAs locate have uniquely experienced significant but similar risk events. One site (WCC) has considerable experience with seismic risks historically, while CCC has not. We expect the former to be more prepared following actualisation of the risk event, while the latter would require significant RM practice changes after the event. The case study period was December 2013 to February 2014. It was almost three years after the CCC risk event and six months after the WCC event, allowing the two organisations to have achieved a level of routineness and consistency in RM practices.

We selected participants from different organisational levels to gain multiple perspectives on RM practices. Within top management, we sought views from councillors/the executive team (termed 'Executive Managers' (EMs)), and General Managers (GMs). Operationally, we approached managers of one business unit with perceived low risks (e.g. library/parking) and the other with high risks (e.g. natural resources (hazards)/business services) (termed 'Operational Managers' (OMs)). Sixteen in-depth semi-structured interviews were undertaken across WCC and CCC. Interviewees' roles were not necessarily matched across both 
organisations, but the sample provides varied perspectives on the dynamics of RM practices within and across site(s). Our interview questions were guided by both RM literature and theory (Nama \& Lowe, 2014). The questions were semi-structured to allow for interviewees to discuss other important aspects, and supplementary questions to arise (Walsham, 2006). Each interview lasted approximately one hour and occurred in a place chosen by the interviewee. All interviews were recorded, transcribed and, along with other data, uploaded to NVivo for subsequent qualitative analysis. Ethics approval was obtained from the relevant university committee. Further, we observed and made diary notes about two public meetings where EMs discussed risk-related issues and RM. These validated and enriched the authors' understanding of RM practice within a "site", especially in a formal setting where different actors interact with material arrangements (e.g. risk reports, PowerPoint, meeting room facilities). Perceived general understandings were validated through careful analysis of transcripts, diary notes and documentary data. For example a free and open discussion observed among WCC EMs in one public meeting was checked against interview data for organisational tolerance of differences in risk-related ideas and opinions.

Interview and observational data were triangulated with documentary sources, including: publicly available websites, annual reports and risk documentation provided by the interviewees. This latter source particularly aids the understanding of rules and teleo-affective structures governing risk practices. Data triangulation increases the validity of findings (Yin, 1993), and enables exploration of the actions and material arrangements under the four elements of the social site ontology framework and their inter-relationships in constituting RM practices.

Importing data into NVivo, enables traceability of the chain of evidence (Yin, 1993). An initial coding tree was developed based on standard RM practice described in organisational risk documentations and our interview guide. This was undertaken by the research assistant and rigorously checked and validated by one of the authors. In the second level of analysis common themes run through each practice task, relating to common understandings across organisational practices and unique RM considerations including rules and structures. Hence the data were recoded into the new nodes in accordance with Schatzki's elements: (i) teleological structures, sub-divided into ends, projects, and tasks, ii) general understandings, iii) practical understandings, iii) rules, and iv) material arrangements. To enable cross-site comparison and synthesis (Yin, 1993), we also established case nodes (i) WCC, and (ii) CCC) and a separate node within each case to code changes in RM practices after the risk event. This 
step was undertaken by two of the authors and validated by the third author. The third level of analysis aims to derive unique insights explaining organisational RM practices. New nodes thus pertain to interactions between Schatzki's key elements. This step was conducted concurrently by all the authors. We then manually coded each sentence, section or paragraph. Each node was printed out for separate and in-depth analysis of all relevant content across multiple sources of data related to a certain concept or issue, to enable validation of an insight through data triangulation as explained above. Furthermore, the different steps of data coding and analysis involved validation and cross-check by different authors, enabling inter-coder triangulation and hence the rigour of the findings and insights gained.

The next section presents findings relating to the RM practices within each site. These arise from the third level of analysis and thus describe the four elements, but more importantly the interactions between these elements that drive the site-specific unique RM insights. To preserve the confidentiality of the interviewees, they are referred to by the respective level of management in the case organisation: EMs, GMs, and OMs and identified by number and organisation (WCC or CCC).

\section{Findings}

\subsection{Local Government in NZ}

LAs represent a significant subset of NZ's public sector, comprising 67 territorial authorities and 11 regional councils. Territorial authorities and regional councils undertake complementary functions, rather than being two levels of sub-national government (Pallot, 2001). Regional councils' core function is environmental management, whereas territorial authorities (LAs on which we focus) are responsible for a wide range of local infrastructure services including: water supply, sewerage, storm water, roads, environmental safety and health, and building control (Department of Internal Affairs, 2014). LAs are financially autonomous and, apart from grants for roading, receive little funding from central government. Their revenue derives primarily from property taxes (rates) and user-charges (Pallot, 2001), and they are accountable to their communities (Local Government Act, 2005). LAs are expected to use public money to provide public goods as understood by an interviewee:

Even if the funding wasn't rate funding for us in our situation, but we were providing public goods, there is a need and expectation... [we've set the] organisation up with a certain benchmark...we will engage and consult with you on what's happening with the 
money, you know we will have transparency...Some of that is legislated but some of it is a public expectation (GM3, WCC).

Thus, meeting legislative requirements and public expectations is the teleology of RM practice in WCC and the interviewee suggests this likely applies to other NZ LAs. Further, since the 1996 Local Government Amendment Act, LAs have been required to be show fiscal responsibility through ten year long-term plans which, since 2002, report financial forecasts and agreed service performance emanating from that (Local Government Act 2005). These plans are audited and supported by annual plans and reports. As such, there is close scrutiny into LAs' operations which could be expected to face political, economic and environmental risks. The LAs studied are now presented, following the lines of Schatzki's elements and drawing on the concept of risk faced by both LAs.

\subsection{Wellington City Council (WCC)}

The WCC is a territorial authority in the Wellington urban area with NZD 6,306 million in public equity. Sixty officially defined suburbs are represented by five Council wards. Its population of 204,000 makes it NZ's third largest city. Seismic risk is a frontal concern due to Wellington's vulnerability. WCC has planned earthquake-resistant buildings for 30 years, normalising management of seismic risks. However, a series of seismic events in mid-2013 triggered strategic rethinking within WCC, to reconfigure how the LA could realise the common objective of meeting legislative requirements and public expectations. The practical understanding of knowing how to manage risks within WCC is shaped by compliance with the RM rules and systems. WCC's pre-existing RM rule mirrors the NZS 4360:2004 RM Standard (WCC, n.d. (Risk Management Framework (RMF)), requiring WCC to use business cases and budgeting to justify and manage different $\mathrm{RM}$ projects. It must ensure that it "has the right systems in place and the right processes to manage [risk] ...to be clear about what the risks are and to try and manage it in a sensible way" (EM2, WCC). To comply with this RM rule, WCC undertook a standard process of identifying, measuring and evaluating risks, discussing and communicating risks and treating risks through internal controls and monitoring (WCC's RMF). For example, they:

...measure risk ... by... both the probability of a failure occurring and the consequence of the failure... so if it's low risk with a high consequence, then it is high risk. And similarly if it is high probability but with a low consequence, it's probably not as high a risk as the last... (GM1, WCC) 
In addition, evaluating risks enables managerial prioritisation of mitigation actions as:

The risk system which we use is like a heat map ...we identify both likelihood and consequence and then there is some criteria around those like financial loss right through whether 'has it got reputation risks, or loss of life?'...And then...you end up with a number which heat maps it from red down to orange down to green... (EM2, WCC)

Hence, there is explicit recognition of the rigour of the current RM systems and the organisation's ability to implement and uphold them.

\subsubsection{New CE's practical intelligibility of "approaching financial sustainability" and the general understanding of "open judgement"}

The current council is known to be a "pretty socially liberal council but also economically adventurous" (EM1, WCC). There is a strong agreement among the WCC interviewees that the council has a particular way of operating, characterised by “open judgement". Open debate is encouraged and differences in opinions are welcome.

We will have healthy debate about things... I perfectly respect people who disagree with [certain ideas] But....they are not saying that the Mayor is stupid to do it...they are saying they disagree for these reasons... (EM1, WCC)

I would think that this organisation is quite open. I have been to the council meeting... I give my numbers and recommendations, and the councillors would discuss. It is quite open. I think the same... at the operational level...we have regular meetings to review and discuss... Everyone can raise the issues they think are important, and have their opinions heard. (GM1, WCC)

As the above quotes suggest, this "open judgement" atmosphere not only resides in RM practice but also permeates other practices and operations within WCC. Due to its widespread and common presence in multiple practices within WCC, Schatzki would term this "open judgement" as the general understanding.

The general understanding of "open judgement" is highly associated with the appointment of a new CE who began three months before the earthquake and chose a leadership style which he continued to practice post-earthquake. He has a personal strategic vision of growing the city: 
"The economy holds the key to our success. We need to invest in the right projects projects that cut our costs, generate income or lead to economic growth, which in turn expands the business rate base”. (WCC, 2013)

The CEO wants to make [the city] more business-friendly... [Business is] actually his strategic vision of growing, rather than growing [the city's] revenue base by...putting rates up. Yes, he's very much of that opportunity and strategic thinking... and the politicians kind of get that as well. (EM3, WCC)

This also suggests that the new CE sought to infuse his own belief of growing the city through the management team and operational staff. His practical intelligibility and approach to financial sustainability is an important part in the development of the general understanding of “open judgement" within WCC: "I'm committed to leading an organisation that delivers, is accessible and open. (WCC, 2013). In particular, the new CE relies on establishing good systems to provide reliable data and placing competent managers in relevant positions to implement top management's policies and actions:

Well I think you start off by putting good managers in place and then...those good managers put the right systems in place to keep an eye on all of those things...Parking revenues, y'know, you've really got to have some good data... we need that data over a number of years to understand the profiles... Yeah you've got to have both really, the levers of good management, the people, the processes, the systems. (EM1, WCC)

With regards to councillors, the new CE influenced them by explaining the rationale of the economic vision for growing the city and respective risks required to realise such vision:

... if economic growth is our big objective as an organisation and we want to do that to grow our rating base so we have sustainable finance to provide good service...I need the right projects and the right sort of economic support arrangements in place to deliver against that agenda. Yeah...they are my initiatives, but we have agreed them as a council. The councillors are generally supportive...but the level of (risk) understanding is low...but here what we've gotta do is make sure that councillors are aware of the risks we are going to be running. (EM1, WCC)

Explanations not only enhance councillors' understanding of the new CE's logic and approach of growing the city but also open the door for them to participate and contribute to further developments in this approach. The new CE's action of bringing councillors on board is further demonstrated by not pre-dictating what the councillors will support (or oppose) and accepting 
the decisions councillors make: "We have to put a strategy forward... we may make a recommendation to them... and then hopefully they will support that, but they might not, they might do something that runs higher levels of risk and then we have to face that. But we will need to inform them the calculated risks we are running." (EM1, WCC)

At the operational level, the new CE invested substantial time after starting (" $a$ whole of the first 2 or 3 months") in "just listening to people". Through regular meetings and conversations with GMs/OMs he tracks targets and budgets, but equally importantly, is informed by these managers: "I have regular meetings with Heads of Services about 25 to 30 people in the organisation at a more senior level so it's, y'know, you have those sort of conversations with them...I do a lot of walkabouts in the organisation just to talk to people and communicate with them." He learned of emergent risks: "we've got lots of issues coming up like the parking contract award where there are new risk issues". His regular contacts with and understanding of GMs/OMs mean they escalated appropriate risk issues to him. This in turn facilitates the 'open judgement' atmosphere at operational level, as these managers see their views and opinions are listened to. Overall, through establishing good systems, placing competent managers, explaining the financial sustainability rationale of growing the city, seeking people's participation and contribution, having regular contacts and meetings, the new CE has rooted his opportunity and strategic thinking into top management and operational staff that contributes to the development of an 'open judgement' general understanding within WCC.

\subsubsection{The general understanding of "open judgement" and operational staff's practical intelligibility of "willingness to try things" and "orchestrations in intelligibility"}

The general understanding of "open judgement" changed individuals' approaches and the RM logic within WCC. Before the earthquake, WCC as a whole was dominated by "riskaversion" (OM1) preferring to "take the easy course rather than actually doing the right thing...i.e. stay the same..." (EM1, WCC). However, encouraged by the new "open judgement" operational and management style, staff have "more of a willingness to try things and if things don't work, y'know don't stop, change, do something different (OM1, WCC). Further, orchestrations in defining risk (the rationale) are accepted. As one of the interviewees explains:

You might get slightly different views on that from different elected representatives so for example [the Council] happens to have a Mayor-bent and flavour... whereas some other participants in the Council process... will probably have a different view. We will get different perspectives around the table about, e.g. what is a strategic risk for the 
Council. It is not driven off some kind off some sort of shared consensus on what they are. (EM3, WCC)

The influence of "open judgement" general understanding on people's practical intelligibility is so strong that the RM principles of "willing to try things" and "orchestrations in RM rationale" begin to transform the prior rule-based practical understanding and RM. Specifically, while continuing to apply the RM rule (for example, calculating residual risk, using a risk matrix and ranking), the approach is becoming flexible and dialectic, with the focus on the long term and opportunity-based risk thinking to risk identification:

Judging what risks to focus on...I think that's more art than science...it's about the level of real risk you might face and a judgement about that... We even need to go beyond that because y'know there is a whole bunch of stuff that lies outside what we already know... We need to be as flexible and forward-looking as we can, to capture that. (EM2, WCC)

I think you have to be cautious about things and you have to choose your risks, and those that you want to mitigate or monitor closely...If you become too risk averse, it just closes things down. Taking calculated risk is the preferred approach. (OM1, WCC)

Other RM activities also evidence practical intelligibility of "willing to try things" and "orchestrations in RM rationale" changing how risk should be handled under rule-based practical understanding. For example, rule-based practical understanding requires RM personnel to rely on public consultations to appreciate the control environment: "Part of [the Council's] role is to listen and take the pulse of the community before making decisions." (WCC, 2013). However, RM personnel actually make their own "open judgement" when determining the level at which such consultations are useful:

If I am completely honest there is the possibility... to get the risk appetite of our ratepayers and that must influence us because Councillors are elected representatives so that has to have an influence. In the end it is a political process. [But] it is unlikely that it is going to cause us to start from the very beginning. (EM2, WCC)

General understanding of "open judgement" has encouraged orchestrations in individuals' understanding of managing risks. Such orchestrations in practical intelligibility facilitate multiple risk interpretations and RM actions, which form various project and task combinations to realise the teleology of meeting legislative and public expectations. 


\subsubsection{Teleological structures disseminate "open judgement" general understandings directly and indirectly through affectivity}

The strong effect of "open judgement" general understanding on operational staff's practical intelligibility of "willingness to try things" towards RM, synchronises with a teleological structure comprising several end-project-task combinations. Based on "open judgement" general understandings, top management disaggregated the common RM teleology (meeting legislative requirements and public expectations) into specific RM goals. These included minimising risks and undertaking effective RM actions, encouraging and improving economic growth, increasing preparedness for earthquakes and reducing their impact, addressing the risks of leaky homes, increasing safety of the workplace and returning sick/injured people to work, and protecting and maintaining assets. Top management also established RM projects and tasks to assist operational staff achieve RM goals. Of particular importance in the teleological structure is the communications/reporting system called 'three-lines-of-defence' (WCC, n.d., $\mathrm{RMF})$.

The 'first line-of-defence' results in operational staff collecting and discussing risk information before reporting to business unit managers. This line-of-defence requires the 'layperson' (Callon 2007) low in the organisational hierarchy (e.g. operational staff) to take ownership and demonstrate accountability for risks upwards to their manager. "[risk information] would go to the unit manager concerned, or... to a team leader depending on what the risk was and what the project was and what the impact [was] going to be" (GM3, WCC). Upwards transparency was explicitly practised by WCC managers: "[I] also take an approach of having in my RM team, people who focus on the particular areas of the business, and they provide a means of questioning and challenging and allowing perhaps sometimes those issues to come up to the surface." (EM3, WCC)

As Callon (2007) recommend, WCC 'laypersons' were encouraged to actively communicate with and seek RM advice from risk experts - the Risk and Compliance team and Audit and Risk Committee. The Risk and Compliance team comprises the second line-of-defence being responsible for "developing the RM framework, monitoring risk registers and reports, undertaking risk reviews and monitoring RM controls", as well as "reporting risk issues" to top management (WCC, n.d., RMF). Internal audit embodies the third line-of-defence, providing assurance and oversight of previous lines-of-defence, and reporting to the Audit and Risk Committee. The Audit and Risk Committee, decide which risks pose certain threats, updating the organisational-wide risk register (a material arrangement) which they monitor 
along with top management. Finally, top management distils possible strategic risks into three strategic risks, clearly defined as "events that affect the achievement of organisational objectives" (GM1, WCC). The teleological 'three-lines-of-defence' structure is underpinned by communicating agreed plans downwards from GMs (in top management team) to operational staff. Within business units, communication of critical risk issues is facilitated through a set of material arrangements including team-based call trees, group texts in the case of emergency, intranet posts, and emails, as noted:

...there is also an increasing integration of RM throughout the whole organisation...so whilst those people at the bottom (not a good term), whilst they don't understand what the term [RM] is, they know what they have to do as far as health and safety, as far as business continuity, as far as making sure they have a call tree in place and all those kind of things. (GM2, WCC)

The upgraded 'three-lines-of-defence' creates a bottom-up and top-down communication hierarchy (Cobb et al., 1995) allowing interactive, frequent, timely and open discussions on RM issues among WCC's top management, operational staff and managers, risk and compliance team and internal auditors. Thus, WCC interviewees are confident that risk communication is honest and open: "we are not trying to hide anything so I think that's positive...people trust what we are saying... we've been really up front" (GM3, WCC). This open and interactive communication hierarchy together with the 'three-lines-of-defence' and other RM projects and tasks signals a sense of importance of dealing with risks in a serious and open-minded attitude to people across WCC.

The sense of importance of dealing with risks was further underpinned by an accounting device, performance development planning (PDP), arousing operational-level staff's affection towards RM (Boedker \& Chua, 2012). Staff are evaluated against a certain grading, which impacts their salary increments (OM1, WCC):

Yes, they will influenced by something [a risk] identified and there are actions expected of them. I don't think there is any doubt about that, because they know that cascades through to performance assessment of them individually. (EM4, WCC)

Risk-related PDP and performance evaluation becomes an effective mechanism to ensure "there is personal commitment [to RM]" (GM2, WCC). "Everybody has objectives around health and safety which have to be met, otherwise they don't receive a certain grading." These influence salary increments: "so the grading is a 1 to 4 . If it is a 2, they might not get a salary 
increase. Or they might still get one [but] a smaller one" (OM1, WCC). Hence, the general sentiment is that RM is important and it is incorporated in PDPs.

\subsection{4. "Open judgement" general understanding influence affectivity and then the use of teleological structures and accounting devices}

As previously discussed, teleological structures (e.g. three-lines-of-defence) and linking RM actions to operational staff's performance evaluation implanted the importance of RM into people's hearts, constructing an affective sense of "materiality" towards RM. This affectivity in turn raised people's attention towards RM and encouraged practising RM on a routine basis. However, these teleological structures and PDPs at the same time may generate risk aversion and curb orchestrations on what risk is, which goes against the "open judgement" attitude the new CE planned for WCC:

To ensure the general understanding of "open judgment" is fully penetrated, an affective element was directly incorporated into the teleology of RM: "Health and safety is a standing item in every meeting. We (recently) adopted a really simple emotive statement, 'everyone has the right to go home from work" (GM2, WCC). This emotive statement mitigates the potential perceived negativity associated with the top-down imposition of teleological structures and risk-linked PDPs. Instead, by communicating the materiality aspect (i.e. RM relates to my rights and personal welfare), the emotive statement makes RM matter to staff and embeds of RM in daily operations and practices. Further, accounting devices are deliberately used flexibly to mitigate people's worry and stress about failing to achieve the goals set in the PDP. By allowing for mistakes and exigencies, WCC aims to preserve and promote "open judgement" in their daily RM practices. It is in this sense that we argue that general understandings affect the design and use of teleological structures and accounting devices through affectivity. The direct incorporation of "affective element" and the flexible use of accounting devices enables a careful balance between holding operational managers accountable for risk-linked KPIs while ensuring that managers do not become risk averse and innovation is curbed.

What we can't do to staff is, tie them so tightly to [KPIs] that they can't experiment or innovate as well. They will make mistakes sometimes, they will do things that are not consistent with the risk plans. For example, if we did all those eight big ideas, one of them might not work, but if all the other seven do...it will be great... we have to actually allow some opportunity. (EM2, WCC) 
As a result, the purpose of the teleological structures and accounting devices was to facilitate decision-making rather than a legitimation tool "to get the boxes ticked". The above findings extends Nama and Lowe (2014) by highlighting that teleological structures and accounting devices should be included in the relationship between general understanding and affections when studying certain organisational practices.

\subsubsection{Implanting fundamental RM changes}

Under the pre-existing RM rule, managers identified risk consequences, likelihoods and mitigation strategies; "then we would come up with kind of what we called a residual risk" (EM3, WCC). However, quantifying residual risk unintendedly diverted mangers' focus from mitigation strategies and the accounting quantification no longer measured residual risk, but was: "focusing on the raw risk without taking all the factors into that raw risk then putting more priority on the mitigation strategies [to manage risk] ...down to an acceptable risk for the Council" (EM3, WCC). Thus, the rule of risk quantification was deemed challenging and hindering to risk identification and evaluation. Furthermore, quantification diverted conversation from important RM questions.

So historically when we have done our risk register...the conversation [was] 'should this be No. 5 or No. 4 or No 3'. We have just moved away from that. [Ranking] masks some of the conversations about next steps, so the conversation should have been 'have you put in mitigations' and 'are you comfortable about those mitigations' and then, coz then it prompts you to have a really simple conversation, but difficult to answer. 'Are you measuring the residual risk or the raw risk?'So when you do it on a ranking basis it poses a risk in itself, but you don't ask or pose yourself the appropriate questions which is 'how to mitigate these'. The new system we have does that.... (GM2, WCC).

The above quote suggests that WCC managers perceive quantifying residual or raw risk hinders "simple conversations" about RM strategies which matter to daily RM practices. Nevertheless, top management and operational staff agreed it was "not possible to define [risk] in a quantitative way" (EM2, WCC), rather a positive qualitative judgmental approach would enable important questions to be asked and answered. RM becomes "a little bit less driven by those rankings and the matrix" and instead driven "largely by the people" (EM3, WCC) and their practical intelligibility. Hence, WCC's RM practice moved from rule-compliance to understandings-based ("a bit more by kind of what is qualitatively the level of risk we can put in place" (EM3, WCC)). Hence, while practical understandings remained unchanged, as 
managers still knew (and followed) how to identify, measure, and assess risk exposure, the practical intelligibility had shifted. The action following risk assessment, under the rulecompliance intelligibility was to rank the risks in the risk register. Under the understandingsbased intelligibility, the discussion focused on the raw risk and mitigation strategies to meet the Council's risk appetite. Hence, whilst quantification-based understandings were still relevant, they contributed to rather than overrode the judgement of the mitigation strategies. In other words, RM becomes "a little bit less driven by those rankings and the matrix" and instead driven "largely by the people" (EM3, WCC).

The shift from rule-based quantification to understandings-based judgement of RM practice is largely attributable to the dissemination of the "open judgement" general understanding within WCC. This general understanding originated from the "approaching financial sustainability" practical intelligibility of the new CE who was appointed three months prior to the earthquake and continued without change subsequent to that risk event. This "open judgement" significantly affects the practical intelligibility of operational staff, disseminated through the use of teleological structures and accounting devices, which in turn actualises affectivity of "mattering". These elements together contribute to the implantation of fundamental change in RM practice to the qualitative identification and evaluation (Mikes 2009) of strategic risks prevailing among all WCC staff levels. This broke the quantitative RM mode based on the pre-existing RM rule. By highlighting the changing of general understanding as important in embedding RM change, this study supplements Hall et al.'s (2015) call for finding appropriate "governance and incentive" changes to match with, and lift the impact of, new RM projects, tasks and devices.

\subsection{Christchurch City Council (CCC)}

We now turn to CCC, the territorial authority for the Christchurch urban area, comprising 13 councillors elected from seven Council wards. It manages NZD7,081 million in public equity and its population is 366,000 . Similar to WCC, the common teleology of RM practice within $\mathrm{CCC}$ is 'meeting legislative requirements and public expectations'. In addition, the practical understanding of risk treatment within CCC is based on the ISO 31000:2009 RM Standard which "provides a consistent language in the consideration of risk across all the CCC activities" (CCC, n.d.). This standard is similar to WCC's, requiring business cases and budgeting to justify and manage RM projects. Applying this rule involves a standard process of identifying and measuring risks, evaluating the likelihood and consequence of risk events, discussing and communicating risks and treating risks through internal controls and 
monitoring. Unlike WCC, CCC previously was unconcerned about seismic risk, not being deemed to be on a seismic fault. Yet, during 2010 and 2011, Christchurch suffered devastating earthquakes, resulting in significant loss of revenue, dramatic property damage to the central business district and 185 citizen deaths. Earthquake devastation was followed by citizens demonstrating against CCC's performance, calling for 'leadership and transparency' to move the city forward. ${ }^{1}$ As such, risk was understood as negatively hindering CCC's timely postearthquake rebuild: "if the city rebuild does not happen on time, it affects the reputation of the council; respond[ing] not in the correct way...there is a reputational risk to the organisation" (GM1, CCC).

\subsubsection{Previous CE's practical intelligibility of "minimising important issues" and the "insular thinking" general understanding}

According to Schatzki (2012b, p.3), general understandings are "elements of practices... and are senses of the worth, value, nature, or place of things, which infuse and are expressed in people's doing and sayings". CCC's general understanding is "insular thinking" as explained:

$Y^{\prime}$ know this is an organisation that was very insular. We had an audit undertaken on communications almost 18 months ago, an independent audit and that identified the fact we are an insular organisation, an insular-looking organisation, we don't extend ourselves out into the community. (EM3, CCC)

Besides "not being open to the community", other evidence of insular thinking in CCC's interactions with its key stakeholders include rarely looking for and communicating signals of "efficiencies" and "value for money" to them (GM1). The "insular thinking" general understanding is further infused in CCC's everyday management and operations practices as this understanding implants "an interesting culture... where there is a whole range of complex behaviour issues going on, and not just an isolated behaviour...coming from this insular (thinking)" (EM3, CCC) .

This "insular thinking" general understanding appears to originate from the practical intelligibility of the previous CE: “he had a very much a 'business as usual approach' that was very insular... [and]instilled a culture of minimising important issues" (EM1, CCC) through refusing to escalate key risks to appropriate top management levels (e.g. councillors) from within operational levels and business units. Another interviewee expressed the view that " $a$

Sachdeva, (2012) 'Protesters threaten rate revolt in Christchurch' downloaded from: http://www.stuff.co.nz/national/6351630/Protesters-threaten-rates-revolt-in-Christchurch 
change in CE will help change that insular thinking" (EM3, CCC), further illustrating the influence of the $\mathrm{CE}$ on the organisation's culture. Besides the $\mathrm{CE}$, the practical intelligibility of other senior managers also contributes significantly to the development of CCC's insular thinking. These senior managers are operationally focused and reluctant to engage in strategic issues:

We had a very good Chief Financial Officer who was quite strategic ... but the remaining members of the team are very operational. They are not very strategic, just sitting around the teacups... We as a team have to consider and address and say 'ok how do we deal with that from a policy perspective'... but there is a real reluctance to consider it, it is very much day-to-day operations stuff...(GM2, CCC)

Despite the existence of teleological structures enabling strategic issues to be brought to top management's attention, senior managers prefer to engage only on operational issues especially those relating directly to their area of responsibility, and relying on internal audit to manage the strategic risks:

It is very much about operational risk not strategic risk... so there is a risk register that goes to the Executive Team (ET) and it is discussed but ... things I was responsible for, certainly get reported but you don't see any active addressing or prioritisation of the work to address those risks. It is not visible to me... (EM3, CCC)

Due to limited resources... only key risks or material risks that will impact on CCC's strategic and business objectives are recorded on the CCC risk register and administered by Internal Audit. (CCC, n.d.)

Similar to the previous CE, these remaining senior executives tend to minimise important issues and prevent the council or the public being informed:

PWC did an independent review... they identified a number of areas of risks that potentially were in breach of the Local Government Act, quite significant pieces of risk. [Xxx] went to present the information and the first words that came out of their mouth was, 'their report doesn't look good, how do we get it changed?' So I was quite flabbergasted at the attitude, and there was strong pressure to change the words to dilute the results. (EM3, CCC).

The above evidence suggests that the "minimising important issues" practical intelligibility of 
the previous $\mathrm{CE}$ and remaining senior managers established a sense of "insular thinking" infusing CCC's operational staff's daily activities.

\subsubsection{The "insular thinking" general understanding and operational staff's practical intelligibility of "independent processing" and "box-ticking"}

This "insular thinking" general understanding moulds the RM practical intelligibility of CCC's employees in two respects: "independent processing" and a "box-ticking" mentality. Employees believe that "independent processing" and "box ticking" underpin RM principles. Hence certain risks are contained within limited functions or business units, rather than being escalated upwards or outwards. First, "independent process" refers to employees' reluctance to engage in substantial communication and coordination with other organisational members on risk matters. The "independent process" RM principle is exemplified in employees' lack of active participation in discussing issues unrelated to their own operational area or expertise in the organisations' risk meetings:

So I have been to the ET, quite a number of times on proposals and you only get interaction from those that are affected by it. The rest will just sit there and they won't consider it, or debate it, or provide any input. And it just reinforces that silo based thinking. So if an area of risk identified doesn't impact one particular group manager, it is not considered important... So that reinforces the operational focus and it dilutes the sort of strategic, collective responsibility. (EM3, CCC)

Second, the general understanding of "insular thinking" also results in a "box-ticking" RM mentality among individuals within CCC. By minimising issues locally and hiding them from the wider organisation through "insular thinking", management advocates compliance as the "golden rule" for managing risk. Compliance is considered more important than dealing effectively with the substance of the risks. In turn, the "box-ticking" mentality has resulted in RM being a late add-on, rather than integrated throughout the decision making process:

People see it as an extra thing they need to do and for some people, 'oh god we need to do a RM assessment or something'. So we will go through and tick-box. But to me, it's got to be an integral part of the way you do your work and not seen as something you tack on at the end. If you tack it on at the end, it's too late... (OM1, CCC)

Operational staff also exhibited the "box-ticking" practical intelligibility for RM as it enables them to gain approval for projects, rather than engaging genuinely with project-based RM. 
Box-ticking, to these operational staff, means getting the (superficial) assurance of managing risks and avoiding escalating issues upwards in the organisation hierarchy.

The practical intelligibility of "independent processing" and "box-ticking" is so strong that such intelligibility overrides the rule-based practical understanding on RM. Employees are well aware of how risks should be managed (according to the local authority's RM rules) as GM1 notes: "we have the expertise and skills... risks are well recorded, identified and reported". However, these "signals of RM" are not accompanied by the necessity to "accept or even actively mitigate those risks right from operational staff through to senior management". The intelligibility of being reluctant to actively manage risks and integrate formal RM as part of decision-making processes is counter to the objective of rule-based practical understanding: "there is reporting of risk but there is no active addressing or prioritisation of the work." (EM3, CCC)

\subsubsection{The influence of teleological structures on "insular thinking" general understandings through affectivity}

To ensure compliance with the RM rule adopted by CCC, a teleological structure exists for upward risk communication:

All of the areas of Council plug into a risk register and...different levels of the organisation look at risk in different ways. So the lower down [staff], they look at the nuts and bolts of the risk and what happens if this happens and that. But then what we do is elevate those risks up generically so that the middle managers, they are more about looking at their area of responsibility and looking at the overall risks in there, not the detailed risks. If the risks are strategic, then they flow right up to the senior management team. (GM1, CCC)

Whether this occurs is debateable. Furthermore, a new rule across all projects and tasks requires cost-effectiveness and provision of value-for-money. To this end, operational and project managers must prepare a business case for all proposed projects, which are reviewed and approved/refused by top management in their regular risk review meetings. A project approved following this is prioritised for capital expenditure funding.

We will be developing a framework for what a business case for the council should look like, it will be based on better business cases but that will be the basis for taking ...capital projects forward, which is a positive step. And in our initial discussions 
it is not just the financial elements, it is the risk elements as well which we have talked about. (GM1, CCC)

In addition to top management's intensive rule compliance efforts, CCC adopted another teleological structure to ensure rules are strictly followed at operational-level. Specifically, a risk expert (the 'business assurance manager') who is responsible for "developing ERM processes and methodologies, and facilitating risk discussions with top management, the Risk and Audit Committee and the Council" (CCC, n.d., RMF). Supported by "laypersons" such as business unit managers and other operational staff, the CCC's business assurance manager's role is similar to WCC's Risk and Compliance team. Different to WCC, CCC's teleological structure does not involve staff accountability as the first line-of-defence but is designed to hold the business assurance manager accountable for RM. This effectively removes operational staff's risk ownership, therefore the teleological structure promotes the sense that external regulations are prioritised rather than improved organisational RM practice. RM is not personalised, nor shown as everyone's responsibility and worthy of attention. This sense of "strict rule compliance to meet external regulations as an insular exercise" is reflected in operational staff's easy-going attitude that was aptly described as "she'll be alright, take it in your stride, we will deal with it (risk) when it happens" (GM2, CCC). In this sense the teleological structure helped craft a sense of "not mattering" towards RM among employees within CCC. An easy-going attitude affection is general and not limited to RM practice, but rather appears as an organisational-level phenomenon as noted above.

Thus, the end-project-task combinations involving "upward risk communication" and the "business assurance manager" for the purpose of meeting external risk management regulations reinforce the general understanding of CCC's insular thinking.

\subsection{4 "Insular thinking" general understanding affects the use of teleological structures via affectivity}

The general understanding of insular thinking towards RM entailed operational staff's affection of "fears of wrong-doings". In a public sector organisation, it is easier to "avoid making a mistake rather than taking a risk and actually sorting it out [as] it is harder to change and improve than staying the same" (EM1, CCC). This preferred position of not doing/the status quo, further reinforced operational staff's attitude on RM as a superfluous addition. This affectivity of "fears of wrong-doings" exacerbates the logic of "independent process" and "box-ticking exercise" to deal with risks, which in turn affects how teleological structures and 
accounting devices are used in RM (Ferlie and Fisher 2013). For example, "[operational-level staff] still have the attitude of spending the money they have budgeted rather than 'how do I deliver something' and then look at the budget issues after that" (EM3, CCC). Neither the budgets, nor the business case requirement (accounting devices) are used widely at operational level, despite the pressure from top management: "There is this real push at management level to use a better business case philosophy, to try and develop business cases here with rigour, ... what is the financial risk, what is the delivery risk, what is the operational risk, what is the reputational risk associated with it and also identifying the value for money for that project" (EM3, CCC). However, these systems were often not used as:

...there was a real reluctance to put data into the system...They just saw it as bureaucracy and at the end of it, 3 or 4 months when the ET put the information in so it could be assessed, you still had projects there like \$10 million road widening, \$20 million better library and that was it, that was the level of business case, or the demonstration of value for money. There is a lot of inertia”. (EM3, CCC)

Staff generally rely on internal audits and the business assurance manager who they perceive will handle the risks and enable them to carry on with "business-as-usual". For operational managers:

I don't think [RM] has much of an impact at all...The [Business Assurance] Manager managed that so at operational level they have [not bothered]. (OM2, CCC)

Whilst WCC emphasised orchestrations in RM practical intelligibility over rules to facilitate decision-making, CCC prioritised superficial commonality achieved through rule compliance to seek legitimation, while failing to change core RM practices and activities.

\subsection{5 "Superficial commonality" for risk compliance and implementing fundamental RM changes}

The interplay between general understanding, practical understanding, practical intelligibility, teleological structures and accounting devices together in CCC led to RM practice being presented as a set of dispersive actions symbolically connected through accounting and other material arrangements to achieve superficial commonality to meet external regulations. Substantially, staff downplayed or diluted the identified problems rather than engaging and solving them.

The attitude is very much, 'oh well we were lucky to get away with that so we don't need to worry too much about that...' There is a real reluctance... [in contrast to] a 
corporate organisation, to acknowledge and deal with risk... We have the staff, we have the expertise across the organisation but the attitude, the acceptance of the need to deal with this is not there. (EM3, CCC)

Further, RM was not integrated at operational level where: "it happens by sort of good luck rather than good planning" (OM1, CCC). For example, business unit managers were unaware of the need to escalate issues, even though: "there was a clear committee structure, so on any particular issue there should be clear governance and council staff interchange" (EM1, CCC). Further demonstrating poor RM communication among operational staff, interviewees seldom mentioned the business assurance manager's role and internal controls, there was no indication of active RM, despite a teleological structure. Hence, CCC's operational staff attended only to risks within their functional responsibility, not elevating risk information to their peers, superiors or risk experts. The lack of open RM communication led to localised and disconnected decisions, and a piecemeal RM approach across CCC:

A number of independent audits have identified that we are extremely silo-orientated as an organisation... If an area of risk identified doesn't impact one particular group manager, it is not considered important; rather than [them considering] as an organisation 'how does this risk need to be dealt with?' So that reinforces the operational focus and it dilutes the sort of strategic, collective responsibility (EM1, $\mathrm{CCC})$.

Top management also exacerbated the limited RM discussion and communications across CCC as they sought to regain authority to issue building consents. This loss was a major blow to the rebuild effort yet, instead of utilising the teleological structure of informing councillors and communicating with operational staff, the $\mathrm{CE}$ attempted to resolve the issue internally and apparently stated: "'Can you get more staff?', 'Yes we can' and it was dealt with there until [it] reached the point of no return" (GM2, CCC). This major impediment to the city rebuild was not advised to elected councillors or other staff, rather the prior CE sought to avoid blame for CCC's negative performance.

Top management's reluctance to use the teleological structures to inform operational staff of risks further reinforced these staff's understanding that risk was some other person's problem rather than requiring a collective organisational effort: "No, no to be honest, unless it's actually forced it won't be accepted in the short-term or even in the medium[-term]. The ability to...actively mitigate those risks, right through to senior management is often 
disregarded." (EM3, CCC). As a result, there was lack of understanding across the organisation on "the financial risk, the financial value-for-money".

The RM practice of "achieving superficial commonality" within CCC inherited from operations prior to the earthquakes began to change following the appointment of a new $\mathrm{CE}$ with a very different intelligibility from the previous CE. Specifically, the new CE has a handson management philosophy, which has started to move the pre-existing "insular thinking" general understandings within CCC to that of "honesty and openness".

I can see it and I can feel it, there is a different motto in the place now, we have an acting $C E$, and whilst it is not related to risk, the first thing that (the CE) did from the get-go...first thing she has done from there, has get her arse off Level 6 and spent endless hours walking the building and eyeballing people and saying... "I'm the acting CE”, putting out very personalised e-mails almost to the point of, I thought it was going to, 'is there no end in sight?'... and being very open... I think that was the lesson that come out the back of that, honesty and openness in what we are doing... (GM2, CCC)

The appointment of the CE was further followed by the election of 10 new councillors out of 14 in total. The new top management team was perceived as "a really, really nice team of people that have come in, with the same motivation to do things differently" (EM1, CCC). A change in the structure and membership of the council has resulted in similar changes in general understandings. Their intelligibility resonated with that of the acting CE, creating a new RM attitude within CCC.

There has been a council election, and the councillors that have come in are more open and transparent...so [a councillor] he is quite happy to say to everyone, 'I stuffed up, I shouldn't have voted for the pay rise... but y'know I'm putting my hand up ... we all make mistakes, please still vote for me'...Coz it's kind of this Kiwi thing around, if you admit your mistake, then we all make mistakes... (GM2, CCC)

Affectivity change was accompanied with the gradual shifting of general understanding from "insular thinking" to "honesty and openness". Whilst in the past, the fear of blame attribution caused a preference for compliance and box-ticking, a new willingness to admit mistakes has reduced this fear, and started a willingness to consider taking more risks and genuinely managing them. Hence, practical intelligibility is gradually moving away from the "boxticking" mentality, to one that embodies more strategic and opportunity thinking. 
So in the last two years, it has changed quite rapidly. So now, we're actively involved in this (strategic thinking) and driving it... and that makes a big difference. And with the changes to the ET there will be more of a strategic focus. (OM2, CCC).

The change of affectivity and practical intelligibility along with the appointment of new $\mathrm{CE}$ resulted in employees' more active use of revised teleological structures. For example, new governance arrangements with clear segregation of duties and responsibilities are now put in place:

I think there was insufficient governance last time and I think the management of risk and risk mitigations is an essential part of any governance. It is variable in the Council, however it is improving, we have a RM framework, so at the governance level, there's the audit and risk committee, and then GMs and the CE have responsibilities and the CE is accountable, the GMs are responsible and all the units underneath have responsibilities around identifying [risk]. All managers are responsible. (OM2, CCC)

While risk was reported to top management before, the new CE takes a more active role in reporting risk and making it informative to councillors, rather than delegating it to the lower management, e.g. the risk manager.

As of this month [we had] the first Council, that information comes by way of a CE report so: building applications this many, granted this many, issues, whatever, any sort of orange lights or red lights. (EM2, CCC)

The frequency of reporting and meeting also increased: "so we as ET meet regularly every week and probably at least every other week, we will be looking at those risks" (EM1, CCC). At the lower levels, the approach to accounting devices also changed. The risk register is monitored actively and used regularly to instigate discussion and risk understanding. Accounting devices become coupled with teleological structures to support organisational learning:

I am on the ET, I also have a management team meeting with my group and so at least every quarter and probably more like every 2 months we go back to the risk register and review it...so it is about that regular going back, reporting back, [asking] have we challenged people in terms of have we got things on. I talk to my managers, they can go back to their teams and they will talk back through their teams as well. (GM1, CCC) 
With the more active use of teleological structures, there is more connectedness between management levels and the voice of lower management was taken more seriously with regards to risk identification and assessment, as opposed to being disregarded as before:

...each of our groups prioritises or ranks their risks and the ET look at those and aggregate them up to something that is more strategic and also adds something to it so they end up with a separate list for the whole organisation... (OM2, CCC)

Overall, despite the earthquake risk event, there was resistance to RM change, with "insular thinking" general understanding and a CE with a "minimising important issues" practical intelligibility. This general understanding, reinforced by certain teleological structures and the affectivity of "fears of wrong-doings", resulted in "independent processing" and "box-ticking" practical intelligibility. However, the new CE and her practical intelligibility is beginning to drive a change in general understanding from "insular thinking" to "honesty and openness", which has already shown effects on affectivity, practical intelligibility and teleological structures within CCC's RM.

\section{Discussion}

Prior research devoted analytical attention to rules, general understandings, practical understandings and teleological structures when drawing on Schatzki's (2002) theoretical framework to study accounting and other organisational practices within a social site (Ahrens \& Chapman, 2007; Jørgensen \& Messner, 2010; Nama \& Lowe, 2014). These studies examining specific organisation practices imply that individuals' practical intelligibilities are impartible components. Indeed, Schatzki (2002, p.246) argues that "the actions and entities people encounter in settings help mould which particular intelligibility factors determine what makes sense for them to do - how they decide to act". Hall et al. (2015) also show how individuals (i.e. risk managers) mobilise a set of tools to gain influence over executives' decision making processes. We extend Hall et al. (2015) to show how individuals' practical intelligibilities influence other Schatzki elements to mobilise changes in RM practice. Hence, our first contribution is in providing evidence of the mutually affecting relationship between practical intelligibility and general understanding in organising and changing RM practices.

On the one hand, our empirics show that CEs' practical intellibilities are an important factor contributing to the development of RM general understandings for both WCC and CCC. Through establishing good systems, placing competent managers, listening to people and bringing people on board, WCC's new CE infused his preference of “approaching financial 
sustainability" into other people's sayings and doings. This process yielded the development of an 'open judgement' general understanding within WCC, which changed the previously widely accepted quantitative risk analysis. This was shown to be evident at top management/ councillor level as well as operational level. The more qualitative RM practice continued even after the earthquake occured. For CCC, the "insular thinking" general understanding originated from the previous CE's practical intelligibility of "minimising important issues". This resulted in a lack of escalation of risk issues and covering up problems within $\mathrm{CCC}$ in general. Changes in "insular thinking" general understanding were resisted following the earthquakes, until the new CE began exerting her "hands-on management" rationality.

On the other hand, our research agrees with Nama and Lowe (2014), that general understanding sets the commonly accepted attitudes people carry in their "doing and saying". We extend Nama and Lowe (2014), by arguing that these commonly accepted attitudes are not only "carried by people" but also significantly shape their practical intelligibility, leading to certain actions and activities. For example, individuals' RM intelligibility in CCC of "independent processing" and "box-ticking" ("willingness to try things" and "orchestrations in intelligibility" within WCC) is rooted in the general understanding of "insular thinking" within CCC (“open judgement” within WCC). These general RM attitudes shape people's mind-sets of how risks should be managed. This 'shaping' effect is so strong that these RM practical intelligibilities dominate/override the rules-based practical understanding in determining individuals' RM actions to meet legislative and public expectations. For example, in CCC, the insular thinking led to a reluctance to manage and mitigate risks, just to 'tick boxes'. Instead, 'open judgment' evident in WCC was robust to orchestrations in the definition of risk and the needs of "willingness to try (different) things", which transforms the previous compliance and quantiative based RM practices.

Our argument as to the mutually affecting relationsip between general understanding and practical intelligibility further develops Nama and Lowe's (2014) additions to Schatzki's theoretical element of general understanding. Schatzki (2002b, p. 75) argues that "practical intelligbility is an individualist phenomenon and consists principally of the features possessed by, or that may be ascribed to, individuals such as a person's goals, affectivity and the projects/tasks that s/he is pursuing". That is, the affectivity of a practice is one important factor leading to individuals' practical intelligibility. In addition, Nama and Lowe (2014) argue that general understanding relates to how things matter, which is reflected in the affectivity dimension of practices. In WCC, the open and interactive communication and the "three lines 
of defence", underpinned by the linking of performance evaluation (and pay rises) to risk practice, disseminated the "open judgement" general understanding and signals to operational staff how RM matters. Differently, the strict rule compliance and the lack of operational staff accountability in RM lines of defence, reinforced the "insular thinking" general understandings and created a sense of "not mattering" towards RM within CCC. Given that affectivity of a practice is closely related to emotions and moods that individuals carry when performing certain actions, this means that general understanding can affect individuals' practical intelligibility through affectivity of a practice and individuals' emotions and moods.

Second, we agree with Nama and Lowe's (2014) finding on the mutually constitutive relationship between general understanding and affective components of teleoaffectvie structures, but extend Nama and Lowe (2014) and Schatzki by proposing the inclusion of teleological structures into such mutually constitutive relationships. We show that end-projecttask combinations and accounting devices may be structured to influence individuals' emotions and moods, which in turn shape general understanding. For example, accounting devices, such as performance evaluation systems linked to individuals' routine RM processes and tasks, can affect their personal desire and welfare, arousing their affections of 'mattering' ("fear of wrong doings"). These affections in turn made operational staff anchor their RM actions to the general understanding expected by top management. The general understanding, through its influences on people's affections and thus practical intelligibility, affects the performativity of teleological structures. These findings on the relationship between teleological structures and affection concur with Boedker and Chua's (2013) idea of understanding accounting as an affective technology. Thus, we call for more attention to be devoted to affection when studying accounting and other organisational practices.

Finally, this study adds to the RM literature by showing the critical roles that general understanding may play in effectuating new risk management practices. The empirical findings from CCC are partially consistent with Fischer and Ferlie (2013) who attribute resistance to RM practice change to individuals' strong emotional attachment to pre-existing RM norms. Different to Fischer and Ferlie (2013), in CCC the resistance to new RM practice began to ebb when new practical intelligibility and teleological structures were introduced after the earthquake by a new CE to shift the general understanding from "insular thinking" to "honesty and openness". The shift of general understanding lessened peoples' emotional attachment to the pre-existing "taken-for-granted" RM practice, which is beginning to drive change. 
The power of shifting general understanding in effectuating new RM practice is more salient in WCC. Specifically, the change of general understanding from rule compliance and quantitative analysis to open judgement and qualitative judgements (due to the new CE's practical intelligibility) immediately exerted its effects on the change of WCC's RM practice. As an example, top management and operational staff moved from a quantitative measuring and ranking of risks to a more qualitative risk assessment to recognise raw risk and mitigation strategies. Our findings on CCC and WCC provide additional support for Hall et al.'s (2015) finding on the importance of individuals' intelligence in effectuating risk management decisions and actions. At the same time, Hall et al. (2015) highlight the need to enact other organisational changes (e.g. corporate governance and incentive changes) to match with and assimilate the intended strategic ends of new RM practice. Our study builds on Fisher and Ferlie (2013) and Hall et al. (2015) by proposing changing the general understanding as an important way of making RM change fundamental and sustainable. This effect is likely due to the mutually constitutive relationship between general understanding and emotions. Altering general understanding may change people's emotions that are important contributors to resistance to RM change. New emotions in turn are likely to fundamentally and persistently change individuals' daily RM activities. More importantly, a change in general understanding would have wide effects across all organisational members. Together with our previous discussion, we argue that executives' practical intelligibility and teleological structures are important resources that organisations can utilise to enact changes in general understandings.

\section{Conclusion}

Our study utilises interviews, observations and documents to understand RM practices and to answer the research question of "how is risk management practice organised and how does it change within LAs?" We make three contributions to the accounting and RM literature. First, we find that practical intelligibility and general understanding mutually affect each other, contributing to the organising and changing of RM practice. With this finding, we extend prior research by arguing the importance of including practical intelligibility and its interactions with other Schatzki's elements when drawing on this theory to study organisational practices. Second, Nama and Lowe (2014) propose to amend Schatzki by documenting a mutually constitutive relationship between general understanding and affective components of teleoaffectvie structures. This study further builds on Nama and Lowe's (2014) proposed addition to Schatzki by advocating the inclusion of teleological structures into the mutually 
constitutive relationship between general understanding and affectivity. Third, prior RM studies exclusively focus on the use of RM framework/mechanisms to bring about better RM practice despite possible failure of such framework/mechanisms to deliver expected outcomes. This study builds on Fisher and Ferlie (2013) and Hall et al. (2015) by proposing changing the general understanding (in addition to adopting RM framework and mechanisms) as an important way of making RM change fundamental and sustainable.

Our study is subject to limitations. We examine only two NZ LAs and this may limit generalisability. The findings could be richer if we had observed RM practices directly. However, we have addressed this limitation by triangulating interviews, observations and documentary data, validating opinions across different interviewees and observing public meetings. Future research should aim to further test Schatzki's social site analysis, to examine the effect of rules, understandings, teleological structures, and accounting on RM practices, in other contexts and time periods. As shown by our study, Schatzki's ontology provides a rich analytical framework to move beyond description or prescription of $\mathrm{RM}$, to uncovering why and how RM practices are organised and change within organisations, especially the public sector.

\section{Acknowledgements}

We acknowledge our research participants and research assistance from Deane Nicholls. We are grateful for feedback from discussants and participants at the 2016 Accounting and Finance Association of Australia and New Zealand Conference and the $8^{\text {th }}$ Asia-Pacific Interdisciplinary Research in Accounting Conference, 2016; presentations at the Zurich University of Applied Science, and the University of Sussex. The feedback from the BAR Editors and two anonymous reviewers is also appreciated.

\section{Funding Sources}

This work was supported by an internal Victoria University of Wellington grant. 


\section{References}

Abernethy, M., Chua, W. (1996). A field study of control system "redesign": the impact of institutional processes on strategic choice. Contemporary Accounting Research. 13, 569-606.

Ahrens, T., Chapman, C.S. (2007). Management accounting as practice. Accounting, Organisation and Society. 32, 1-27.

Anderson, S.W., Christ, M.H., Dekker, H.C., Sedatole, K.L. (2015). Do extant management control frameworks fit the alliance setting? A descriptive analysis. Industrial Marketing Management. 46, 36-53.

Arena, M., Arnaboldi, M. \& Azzone, G., (2010). The organizational dynamics of Enterprise Risk Management. Accounting, Organisation and Society. 35, 659-675.

Barrett, P. (2005). Future Challenges for Risk Management in the Australian Public Sector. Australian National Audit Office, Canberra.

Beasley, M.S., Branson, B.C., Hancock, B.V. (2010). Developing key risk indicators to strengthen enterprise risk management. ERM Initiative at North Carolina State University and the Committee of Sponsoring Organizations of the Treadway Commission, Raleigh, NC.

Boedker, C., Chua, W.F. (2013). Accounting as an affective technology: A study of circulation, agency and entrancement. Accounting, Organisation and Society. 38, 245-267.

Bromiley, P., McShane, M., Nair, A., Rustambekov, E. (2015). Enterprise risk management: Review, critique, and research directions. Long Range Planning. 48, 265-276.

Bruno-Britz, M. (2009). The age of ERM. Bank Systems \& Technology, 1 (February), 2.

Bryson, J.M. (1988). A strategic planning process for public and non-profit organisations. Long Range Planning. 21, 73-81.

Callon, M. (2007). What does it mean to say that economics is performative, in: MacKenzie, D., F, M., Siu, L. (Eds.), Do economists make markets. Princeton University Press, Princeton, NJ, pp. 311-357.

CFO Research Services, Towers Perrin. (2009). A Qualied Commitment to DB Plans: Risk Management amid a Steep Downturn. Boston, MA: CFO Publishing Corp 
Christchurch City Council (CCC) (n.d.) internal documents including Risk Management Framework (RMF).

Clarke, C.J., Varma, S. (1999). Strategic risk management: the new competitive edge. Long Range Planning. 32, 414-424.

Cobb, I., Helliar, C., Innes, J., 1995. Management accounting change in a bank. Management accounting research, 6(2), pp.155-175.

Collier, P.M., Berry, A.J., Burke, G.T. (2007). Risk and management accounting: best practice guidelines for enterprise-wide internal control procedures. Elsevier.

Collier, P.M., Woods, M. (2011). A comparison of the local authority adoption of risk management in England and Australia. Australian Accounting Review. 21, 111-123.

Committee of Sponsoring Organisations of the Treadway Commission (COSO) (2004). Enterprise Risk Management Framework. COSO, New York.

CPA Australia (2002). Public sector risk management: A state of play. Public Sector Centre For Excellence, Melbourne.

CPA Australia (2014). Pre-Budget Submission. Melbourne: CPA Australia.

Crawford, M., Stein, W. (2004). Risk management in UK local authorities: The effectiveness of current guidance and practice. International Journal of Public Sector Management. $17,498-512$.

Department of Internal Affairs (2014). Local Government in New Zealand - local councils.

Desender, K.A. (2007). On the Determinants of Enterprise Risk Management Implementation. Enterprise IT governance, business value and performance measurement, Shi Nan Si, Silvius Gilbert, eds., IGI Global, 2011. Available at SSRN: http://ssrn.com/abstract=1025982 Google Scholar .

Fischer, M.D., Ferlie, E. (2013). Resisting hybridisation between modes of clinical risk management: Contradiction, contest, and the production of intractable conflict. Accounting, Organizations and Society. 38(1), pp.30-49.

Florio, C., Leoni, G. (2017). Enterprise risk management and firm performance: The Italian case. The British Accounting Review. 49(1), 56-74.

Gurd, B., Helliar, C. (2017). Looking for leaders: 'Balancing' innovation, risk and management control systems. The British Accounting Review. 49(1), 91-102. 
Hall, M., Mikes, A., Millo, Y. (2015). How do risk managers become influential? A field study of toolmaking in two financial institutions. Management Accounting Research. 26, 322.

Horton, J., Macve, R., Struyven, G. (2004). Qualitative research: experiences in using semistructured interviews. In: The Real Life Guide to Accounting Research. 339-357.

Jørgensen, B., Messner, M. (2010). Accounting and strategising: A case study from new product development. Accounting, Organisation and Society. 35, 184-204.

Kleffner, A.E., Lee, R.B., McGannon, B. (2003). The effect of corporate governance on the use of enterprise risk management: Evidence from Canada. Risk Management and Insurance Review. 6(1), 53-73.

Lim, C.Y., Woods, M., Humphrey, C., Seow, J.L. (2017). The paradoxes of risk management in the banking sector. The British Accounting Review. 49(1), 75-90.

Mahama, H., Yu Ming, C. (2009). Currency options trading practices and the construction and governance of operational risk: a case study. Accounting, Auditing and Accountability Journal. 22(4), 626-660.

McCrae, M., Balthazor, L. (2000). Integrating risk management into corporate governance: the Turnbull guidance. Risk Management. 35-45.

Meidell, A., Kaarbøe, K. (2017). How the enterprise risk management function influences decision-making in the organization - A field study of a large, global oil and gas company. The British Accounting Review. 49(1), 39-55.

Mikes, A. (2009). Risk management and calculative cultures. Management Accounting Research. 20, 18-40.

Mikes, A. (2011). From counting risk to making risk count: Boundary-work in risk management. Accounting, Organisation and Society. 36, 226-245.

Mikes, A., Kaplan, R.S. (2013). Towards a contingency theory of enterprise risk management. Harvard Business School Working Paper 13-063., Harvard Business School, Boston MA.

Nama, Y., Lowe, A. (2014). The 'situated functionality' of accounting in private equity practices: A social 'site' analysis. Management Accounting Research. 25, 284-303.

New Zealand Government (2005) Local Government Act: 2005, Wellington. 
Paape, L., Speklè, R.F. (2012). The adoption and design of enterprise risk management practices: An empirical study. European Accounting Review. 21, 533-564.

Pagach, D., Warr, R. (2011). The characteristics of firms that hire chief risk officers. Journal of Risk and Insurance. 78(1), pp.185-211.

Pallot, J. (2001). Local government reform in New Zealand: Options for public management as governance. University of Canterbury.

Power, M. (2004). The risk management of everything. The Journal of Risk Finance. 5, 58-65.

Power, M. (2007). Organized uncertainty: Designing a world of risk management. Oxford University Press.

Power, M. (2009). The risk management of nothing. Accounting, Organization and Society. $34,849-855$.

Schatzki, T.R. (2001a). Introduction: Practice theory, in: Schatzki, T.R., Cetina, K.K., Savigny, E.v. (Eds.), The Practice Turn in Contemporary Theory. Routledge, London, pp. 1-14.

Schatzki, T.R. (2001b). Practice mind-ed orders, in: Schatzki, T.R., Cetina, K.K., Savigny, E.v. (Eds.), The practice turn in contemporary theory. Routledge, London, pp. 43-55.

Schatzki, T.R. (2002). The site of the social: A philosophical exploration of the constitution of social life and change. University Park: The Pennsylvania State University Press.

Schatzki, T.R. (2012). A primer on practices, Practice-based education. Springer, pp. 13-26.

Strauss, A., Corbin, J., (1998). Basics of qualitative research techniques. Thousand Oaks: Sage publications.

Themsen, T.N. (2014). Risk management in large Danish public capital investment programmes, Copenhagen Business School.

Vinnari, E., Skærbæk, P. (2014). The uncertainties of risk management: A field study on risk management internal audit practices in a Finnish municipality. Accounting, Auditing and Accountability Journal. 27, 489-526.

Walsham, G. (2006). Doing interpretive research. European Journal of Information Systems. $15,320-330$.

Weick, K.E., Roberts, K.H., 1993. Collective mind in organizations: Heedful interrelating on flight decks.Administrative science quarterly, pp.357-381. 
Wellington City Council (WCC) (n.d.) internal documents including Risk Management Framework (RMF).

Wellington City Council (WCC) (2013) WCC Annual Report, Wellington.

Woods, M. (2009a). A contingency theory perspective on the risk management control system within Birmingham City Council. Management Accounting Research. 20, 69-81.

Woods, M. (2009b). Risk management in organisations: An integrated case study approach. Routledge, Abingdon, Oxon.

Yin, R. (1993). Applications of Case Study Research, Beverly Hills, CA, Sage.

Zolkos, R. (2008). Financial crisis shows real need for ERM. Business Insurance. 6, 6. 